(C) В.О. Евсеев

DOI: http://doi.org/10.15350/24097616.2020.1.25

\title{
УДК 330
}

\author{
СТРУКТУРНО - СЕМАНТИЧЕСКОЕ МОДЕЛИРОВАНИЕ РАЗВИТИЯ \\ СОЦИАЛЬНО-ЭКОНОМИЧЕСКИХ И ОБЩЕСТВЕННЫХ ОТНОШЕНИЙ \\ В.О. Евсеев
}

\author{
Евсеев Вадим Олегович, \\ доктор экономических наук, профессор кафедры \\ политологии и социологии, Российский экономический \\ университет им. Г.В. Плеханова, Россия, Москва. \\ РИНЦ SPIN-код: 3997-1213 \\ E-mail:manrus@mail.ru
}

\begin{abstract}
Аннотация. Основным вопросом исследования является построение структурносемантической модели общественных отношений и получение количественных показателей между участниками/акторами этих отношений по структурной иерархии их взаимодействия. Целью исследования являлось изучить «внутреннюю кухню» интересов между акторами общественных прочессов, выявить их ролевые установки при формировании общественных отношений, выявить характеристики культуры общественных отношений, как платформы, на которой держится вся иерархическая структура. Результаты. По каждому иерархическому уровню получены лепестковые диаграммы, данные которых показывают приоритетные уровни межличностных предпочтений для акторов общественных отношений; уровни предпочтений совместимости их интересов; уровни предпочтения в этапах проектирования общественных отношений и общественных прочессов. Выводы: Результаты моделирования показали: 1.что наличие системной разбалансированности в существующих сочиальноэкономических и общественно-политических процессах, что в первую очередь, связано с невысоким уровнем общественной культуры, особенно с культурой общественного сознания и культурой общественного поведения; 2. личностные интересы у акторов общественных отнотений превалируют над общественными, т.к. показатель «взаимодополнение» всегда находится на периферии интересов.
\end{abstract}

Ключевые слова: структурно-семантическая модель, акторы общественных отношений, совместимость по позициям, этапь реализации общественных отношений, режимы существования общественных отношений, общественная культура.

\section{STRUCTURAL AND SEMANTIC MODELING OF DEVELOPMENT SOCIO-ECONOMIC AND SOCIAL RELATIONS \\ V.O. Evseev}


Vadim O. Evseev, The doctor of economic sciences, professor Faculties politics and sociology, Plekhanov Russian University of Economics, Moscow, Russian Federation. RSCI SPIN-code: 3997-1213 E-mail:manrus@mail.ru

\begin{abstract}
The main issue of the research is the construction of a structural and semantic model of public relations and obtaining quantitative indicators between participants/actors of these relations according to the hierarchy of their interaction. The purpose of the study was to study the "inner kitchen" of interests of the local actors of social processes, to identify their role settings in the formation of public relations, to identify the characteristics of the culture of public relations as a platform on which the entire hierarchical structure is based. Results. For each hierarchical level, petal diagrams are obtained, the data on which show priority levels of interpersonal preferences for actors of public relations; levels of preferences for compatibility of their interests; levels of preferences in the stages of designing public relations and social processes. Conclusions: the simulation Results showed: 1.that the presence of a systemic imbalance in existing socio-economic and socio-political processes is primarily associated with a low level of public culture, especially with the culture of public consciousness and the culture of public behavior; 2. personal interests of actors in public relations prevail over public ones, since the indicator "complementation" is always on the periphery of interests.
\end{abstract}

Keywords: structural and semantic model, actors of public relations, compatibility by positions, stages of implementation of public relations, modes of existence of public relations, public culture

\title{
Представление
}

Моделирование социально-экономических и общественных отношений всегда было интересной темой не только для управленцев, экономистов ${ }^{1}$, социологов ${ }^{2}$, политологов ${ }^{3}$, но и для специалистов по исследованию и моделированию сложных социально-экономических систем ${ }^{4}$, которые стали привносить свои методы исследования для изучения общественных процессов.

Есть достаточно много хороших отечественных книг по моделированию социальноэкономических и общественных процессов, которые носят систематизирующий характер. Также необходимо отметить, что теория моделирования уже давно нашла практическое применение в зарубежных политических кругах, особенно в США. Это объясняется прикладными приоритетами: в изучении общественного мнения и механизмов его влияния на выбор социально-экономических стратегий со стороны правительства, в развитии

\footnotetext{
${ }^{1}$ Орлова, И.В., Половников В.А. Экономико-математические методы и модели: компьютерное моделирование:Учеб. Пособие.- 3-е изд., перерб.идоп.-М.: Вузовский учебник: ИНФРА-М, 2011.-389c.

Лычкина Н.Н. Имитационное моделирование экономических процессов:Учеб. Пособие.- М.: ИНФРА-М.-254 с.

${ }^{2}$ Колесин И.Д. Принципы моделирования социальной самоорганизации: Учебное пособие.-СПб: Изд-во «Лань», 2013. - 288 с

${ }^{3}$ Ожиганов Э.Н. Моделирование и анализ политических процессов: Учебное пособие. - М.: РУДН. 2009. - 189 c.

Петухов А. Ю. Моделирование политических и социальных процессов: учебное пособие. - Н.Новгород: Нижегородский государственный университет им. Н.И. Лобачевского, 2015. - 141 с.

${ }^{4}$ Теория и методы в современной политической науке: Первая попытка теоретического анализа / под ред. С.У. Ларсена; [пер. с англ. Е. А. Жуковой]. - М.: РОССПЭН, 2009. - 751 с.
} 
компьютерных и сетевых технологий, в создании программ искусственного интеллекта, в разыгрывании вариативных сценариев использования экономической и политической сфер в международной конкурентной борьбе: за сферы военно-политического, финансовоэкономического, географического и мировоззренческого влияния.

Разработка моделей, так и работа с ней, позволяет использовать модель:

1. для более глубокого осмысления действительности $[1,2,4,5]$;

2. как средство для мозгового командного штурма;

3. как средство обучения, тренажа и выявления компетенций;

4. как инструмент прогнозирования [6,7];

5. для развития логики и вариативности политического мышления, особенно при проведении модельных экспериментов. В своё время (1975 г.) американский учёный Р. Шеннон написал книгу по моделированию сложных систем, которую назвал «Имитационное моделирование систем - искусство и наука» ${ }^{5}$, с акцентом на искусство мыслить при разработке моделей. Необходимо отметить, что понятие «отношения» предполагают наличие субъектов отношений, процедуры отношений, приоритетов отношений, культуры отношений, историю отношений - это как минимум. Из сказанного мы видим наличие сложно-подчинённой, иерархической системы отношений, в которых с учётом множества факторов, в условиях конфликтов или консенсуса, формируются программы общественного развития.

\section{Методология}

Алгоритм работы структурно-семантической модели. В основе алгоритма работы структурно-семантической модели лежит метод анализа иерархий (МАИ) (Analytic Hierarchy Process - AHP) американского ученого Т. Саати ${ }^{6}$. Данный метод является математическим инструментом системного подхода к сложным проблемам принятия решений и предполагает декомпозицию проблемы на простые составляющие части и обработку суждений исследователя. Относительная значимость выражается численно в виде векторов приоритетов. Полученные таким образом значения векторов являются оценками в шкале отношений и соответствуют так называемым жестким оценкам. МАИ не предписывает лицу, принимающему решение, какого-либо «правильного» решения, а позволяет ему в интерактивном режиме найти такой вариант (альтернативу), который наилучшим образом согласуется с его пониманием сути проблемы и требованиями к ее решению.

Алгоритм применения метода следующий:

1. Определение иерархий целей;

2. установление приоритетов критериев методом попарного сравнения;

3. установление приоритетов альтернатив по каждому критерию;

4. определение глобального приоритета альтернатив.

Иерархическая структура - это графическое представление проблемы в виде перевернутого дерева, где каждый элемент, за исключением самого верхнего, зависит от одного или более выше расположенных элементов.

Входная информация для модели: 1. выбранные категории общественных отношений; 2. распределение категорий по структурным уровням; 3. задаваемая величина значимости категорий в их связи с другими уровнями. Задаются предельные величины значимости атрибутов выбранных категорий по соответствующим структурным уровням.

Выходная информация в модели: числовые характеристики атрибутов категории «Общественная культура», взаимосвязи акторов общественных отношений, области их

\footnotetext{
${ }^{5}$ Шеннон Р. Имитационное моделирование систем - искусство и наука. - М.: Мир,1978. -418 с.

${ }^{6}$ Саати Т., Керис К.,Аналитическое планирование. Организация систем: Перевод с англ.- М.: Радио и Связь, 1991, - 292 c.
} 
интересов и темами их приоритетной совместимости.

Построение структурно-семантической модели. В виде атрибутов модели были выбраны следующие элементы общественных отношений:

1. Акторы общественных отношений - 1. Президент; 2. правительство; 3. политические партии; 4. гражданское общество; 5. лоббисты; 6. элита (мнемоническое отражение в модели - Актор);

2. Совместимость по следующим позициям - 1. общее понимание опасностей и угроз; 2. совместимость целей; 3. общность интересов; 4. совместимость ценностей; 5. совместимость ресурсов; 6. взаимодополнение (мнемоническое отражение в модели - Совм);

3. Основные этапы реализации общественных отношений -1 . институализация интересов; 2. формулирование гражданской воли; 3. реализация гражданской воли; 4. принятие организационных решений; 5. принятие управленческих решений (мнемоническое отражение в модели - Эт.Реал);

4. Режимы существования общественных отношений - 1. конструирование; 2. функционирование; 3. развитие; 4. упадок (мнемоническое отражение в модели - Реж.Сущ);

5. Общественная культура в системе общественных отношений - 1. культура общественного сознания; 2. культура общественного поведения; 3. культура функционирования общественных институтов (мнемоническое отражение в модели Пол.Культ);

Структура модели представлена на рисунке 1, между семантическими/смысловыми категориями модели формируются связи, и задаётся их значимость в интервале от 1 до 9. Уровень связей/значимости определялся на основе мониторинга состояния общественнополитической и социально- экономической системы, а также профессиональных оценок ведущих экспертов.

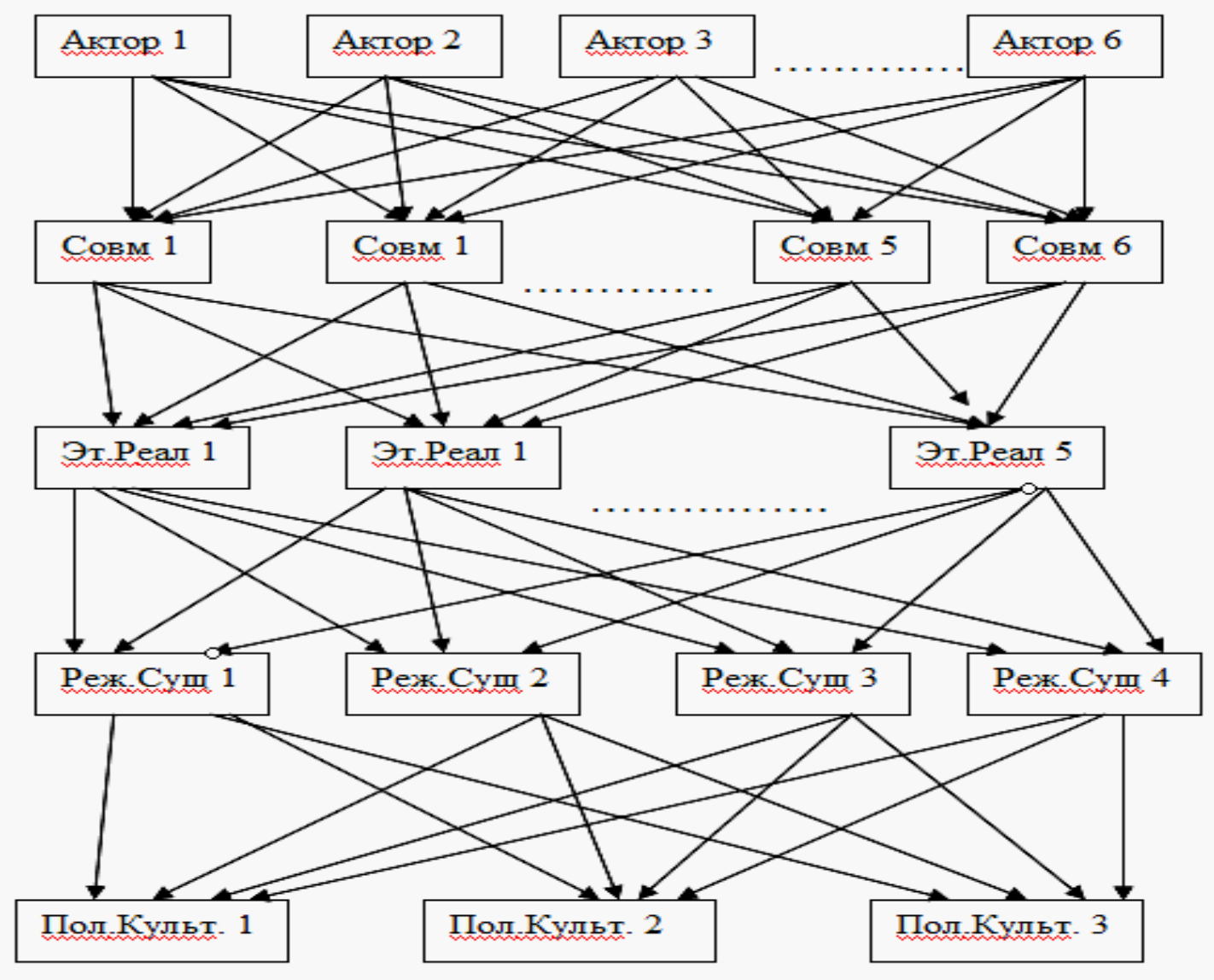


Рис. 1. Структурно-семантическая модель значимости общественной культуры в системе развития общественных отношений/процессов

\section{Результаты}

Интерпретация полученных результатов структурно-семантического моделирования.

1. Совместимость основных элементов общественных отношений. На основе корреляционного анализа совместимости акторов общественных отношений/процесса была составлена лепестковая диаграмма (см. Рис.2.), из которой видны приоритеты отношений между акторами общественных отношений.

Как видно из Рис. 2., гражданское общество находится на периферии интересов Президента и правительства. У Президента на 1-м месте по приоритету находится институт элиты. У Правительства на 1-м месте по приоритету находится институт лоббирования, на 2м месте - институт политических партий и только на 3 месте - институт Президента. У элиты на 1-м месте находится институт Президента, на 2-м месте - гражданское общество.

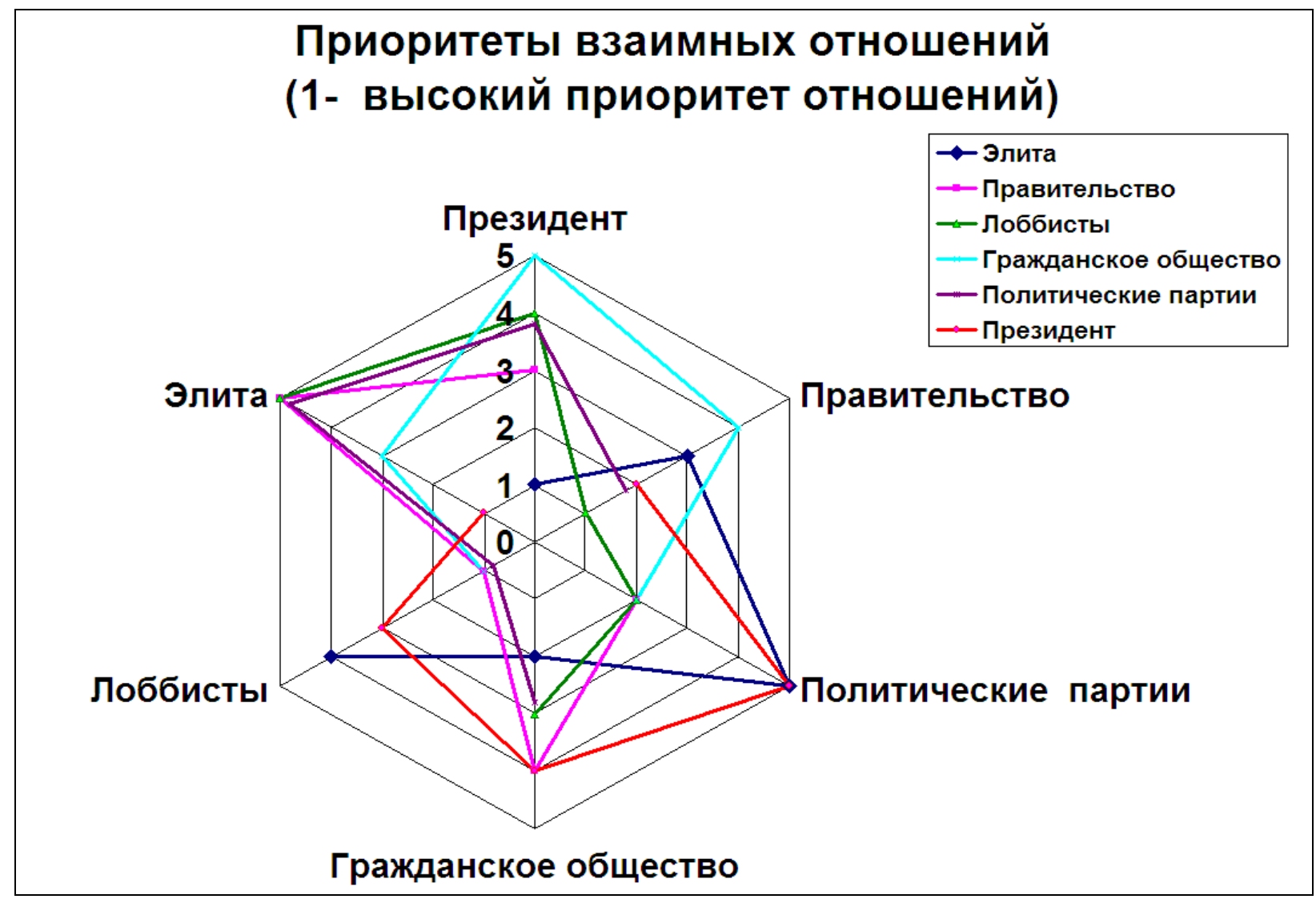

Рис. 2. Распределение приоритета взаимных отношений между акторами общественного процесса (по результатам моделирования)

На Рис.3. приводится лепестковая диаграмма совместимости интересов акторов общественного процесса, это позволяет видеть внутреннюю иерархию ценности/важности отношений между акторами общественного процесса. Она позволяет правильно формировать и акцентировать повестку и вектор отношений при обращении к акторам общественного процесса, позволяет сделать выводы о том, кто входит в первый (самый приближённый) круг отношений, и т. д. Данные Рис.3. также показывают, чьи вопросы 
рассматриваются в первую очередь, а какие - в последнюю очередь. Зная процедурную сторону отношений, можно прогнозировать сроки рассмотрения и решения соответствующих вопросов.

Как видно из Рис.3., у всех акторов общественного процесса имеется своя система приоритетов выбора совместимостей. Значимость выбора тем совместимости отношений: 1 е место - Совместимость Ресурсов; 2-е место - Совместимость Целей; 3-е место Понимание Угроз; 4-е место - Совместимость Ценностей; 5-е место - общность Интересов; 6-е место - Взаимодополнение.

Рассмотрим, для примера, приоритеты совместимостей у Президента: на 1-м месте у него стоит проблема «понимание угроз», на 2-м месте - «совместимость целей», на 3-м «совместимость ресурсов». Для примера рассмотрим категорию «взаимодополнение», которая располагается на последнем месте.

О чём это может говорить? Если продолжить ассоциативное восприятие категории «взаимодополнение», то в связи с ней можем рассматривать категорию «консенсус», категорию «гармония» или «социальная/общественная напряжённость».

Наличие «общности интересов» и «взаимодополнение» на последних местах говорит о наличии существенных деформаций, как в социальной стратификации, так и в гражданском сознании акторов общественных процессов [5].

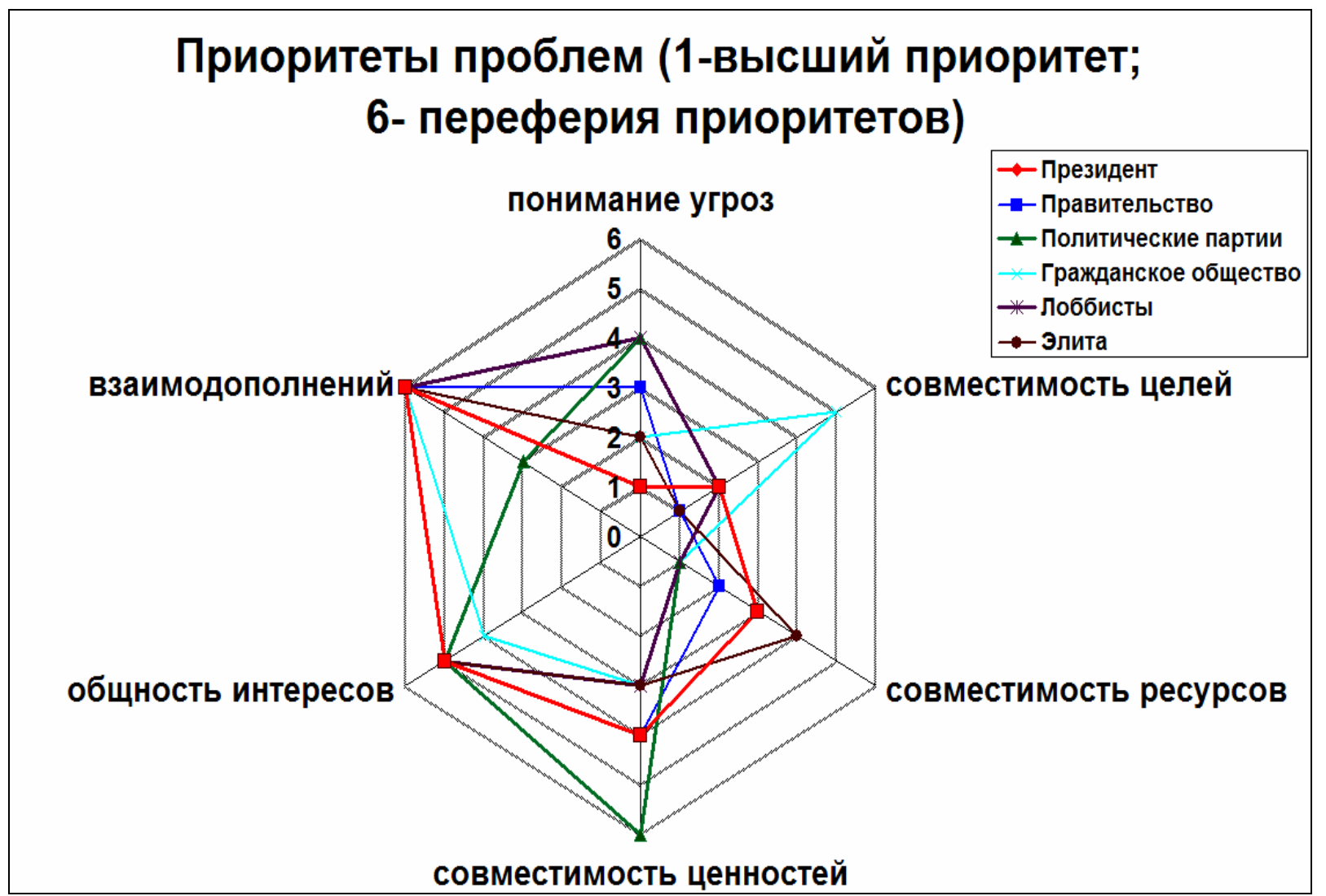

Рис. 3. Распределение значимости/приоритетности рассматриваемых совместимостей между акторами общественного процесса (по результатам моделирования)

Данные Рис.3., является иллюстративным и аналитическим дополнением к категории «политическая кухня» (включает в себя как элементы публичной политики, так и закулисные маневры и интриги, негласные соглашения и договоренности, и прочие скрытые механизмы выработки решений), где первоочередной повесткой общественного процесса является 
распределение ресурсов между акторами общественной деятельности.

2. Основные этапы реализации общественного процесса. На основе корреляционного анализа были получены данные о значимости совместных интересов для каждого этапа реализации общественного процесса. Также были выявлены различия в перечне классических этапов последовательности реализации общественного процесса от фактических приоритетов в очерёдности реализации этапов. На Рис.4. приведены полученные результаты.

Как видно из Рис.4., в основных этапах последовательности реализации общественного процесса имеются существенные деформации. Так, в общепринятом понимании, реализация общественного процесса всегда начинается с этапа «институализации интересов», в нашей модели видно, что на первом месте стоит «реализация гражданской воли», возможно, это говорит об определённом уровне неформализованного стиля управления, когда решения сверху, как бы принимаются на основании решений снизу, без учёта интересов. Этап «принятие управленческих решений», который стоит на 2-м месте (вместо последнего), свидетельствует: в общественном процессе ставку делают на эффективное управление (эффективные управленцы). Но т.к. этап «принятие организационных решений» находится на последнем месте (вместо 2-го места), то таким образом создаются предпосылки: когда общественный процесс столкнётся с организационным хаосом в социально-экономической и общественно-политической сферах, что приведёт к социально-экономической напряжённости.

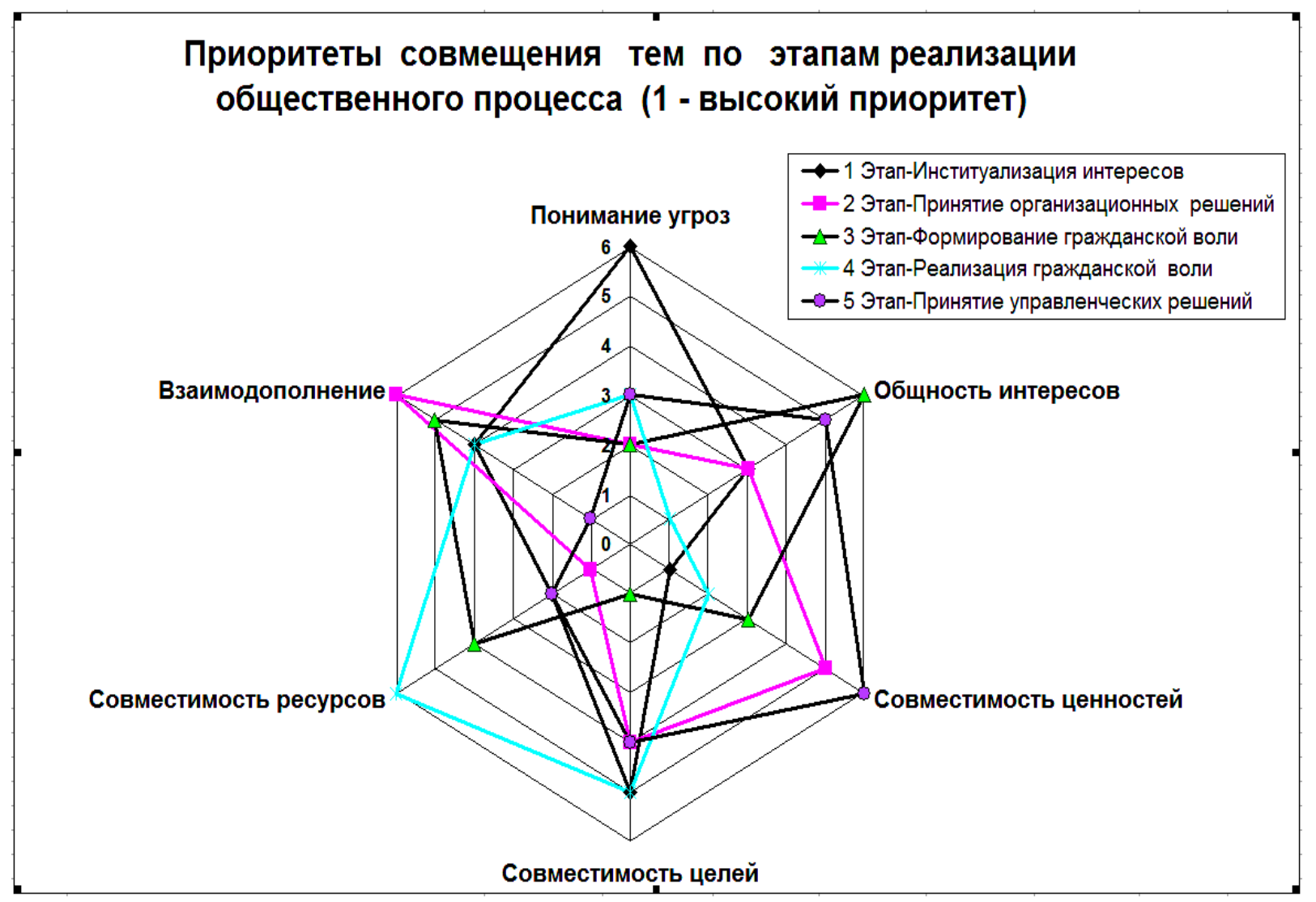

Рис. 4. Распределение значимости рассматриваемым тем совместимостей по этапам реализации общественного процесса (по результатам моделирования)

3. Четыре этапа существования политических процессов. Необходимо отметить, что категория «конструирование», как и другие категории этого уровня структурно- 
семантической модели, не абстрактные, а прикладные понятия. В нашем случае мы рассматриваем категорию «конструирование» в контексте различных этапов развития общественного процесса $[9,10]$. На основании корреляционного анализа и других числовых показателей был построен Рис.5.

Краткий анализ результатов (Рис.5.) показывает, что на первых трёх этапах развития общественного процесса доминирует категория «гражданская воля», и только тогда, когда общественный процесс попадает в фазу упадка, подключаются профессиональные управленческие и организационные решения.

По полученным модельным данным, этапы общественных отношений для акторов распределяются по значимости следующим образом: 1-е место - этап развития; 2-е место этап функционирования; 3-е место - этап конструирования; 4-е место - этап упадка. Также модель показала, что категория «институализация интересов» от этапа к этапу «скатывается» вниз, а категория «конструирование», которая занимает третье место по значимости, говорит что общественный процесс, в контексте общественного развития, не имеет внутреннего понимания и логики развития и возникает как ситуационное развитие. Результаты, представленные на Рис.5., является ключевыми для понимания технологической последовательности при проектировании общественных отношений: на каждом этапе должна быть соблюдена очерёдность- 1. институализация интересов; 2. принятие организационных решений; 3. формирование гражданской воли и т.д. Изменение очерёдности говорит или об отсутствии компетентности или о высоком уровне общественнополитического волюнтаризма, который игнорирует объективные законы общественной жизни, общественного процесса.

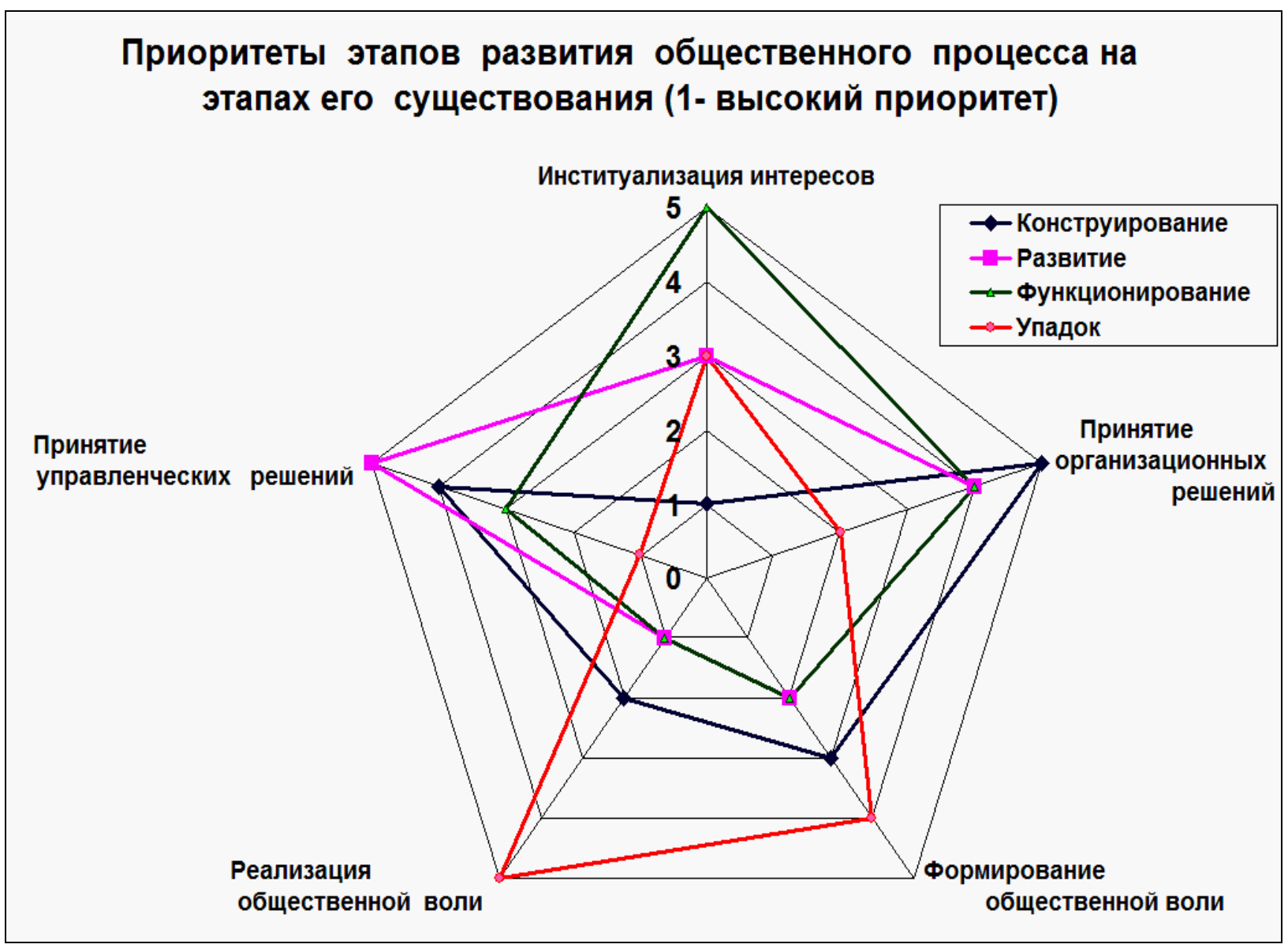

Рис. 5. Приоритеты рассмотрения этапов развития общественных отношений 
на различных этапах существования общественного процесса

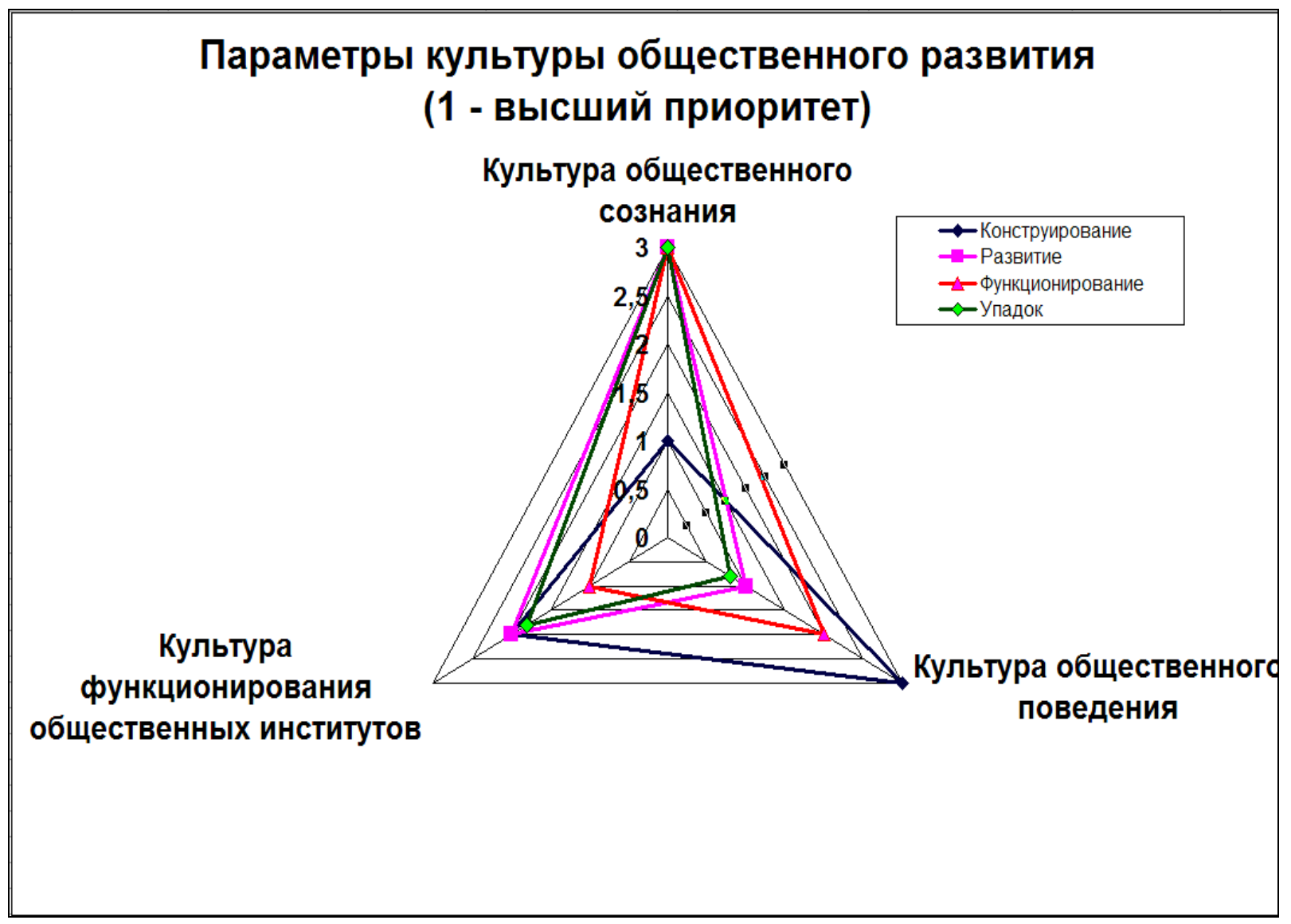

Рис. 6. Значимость атрибутов общественной культуры для этапов существования общественных отношений (по результатам моделирования)

4. Общественная культура в общественных отношениях. Как отмечалось ранее, невозможно проектировать этапы развития общественных отношений без участия культуры общественного сознания, культуры общественного поведения и культуры функционирования общественных институтов. И что будет с общественной системой и общественными отношениями, если общественная культура не отвечает необходимым требованиям? Модель выявила большое количество деформаций на всех уровнях иерархий, что должно соответствовать наличию деформаций в исходном звене - культуре общественных отношений. На основе аналитических расчётов и корреляционного анализа были получены результаты, представленные на Рис. 6., из которого наглядно показано значимость атрибутов общественного культуры для различных этапов жизни общественных отношений.

Как видно из Рис.6., наибольшее влияние на общественные отношения оказывает культура функционирования общественных институтов, культура общественного сознания стоит на последнем месте. Это говорит, как о высоком уровне неопределённости мировоззренческих стандартов в обществе, так и о наличии «управляемого хаоса», который появился из-за невнятной социально-экономической и общественной стратегии развития со стороны верхнего эшелона власти. Только на этапе конструирования, общественное сознание было на первом месте, на всех остальных этапах общественного развития, общественное сознание находилось на периферии интересов

\section{Выводы}


1.Подводя итоги полученных результатов структурно-сематического моделирования (см. Рис.6.), можно сделать вывод, что поведение акторов общественного процесса в первую очередь опирается на культуру функционирования общественных институтов (показатели которых чуть выше среднего значения); во вторую очередь - на культуру общественного поведения (показатели которого чуть ниже среднего значения); в третьих, - культура общественного сознания находится на низком уровне.

2. Состояние и влияние общественной культуры на этапах «развития» и «функционирования» таково, что эти этапы находятся в противофазе с этапом «конструирования», т.е. мы имеем дело со взаимоисключающими процессами (коэффициенты корреляции с обратным знаком).

3. Результаты моделирования выявили серьёзные предпосылки к проигрышу общественной культуры России, как одной из важнейших форм консолидации гражданского общества. И в этом плане, гражданское общество становится удобной сущностью для манипулирования им, для уменьшения его влияния на процедурные моменты развития общественных процессов в его интересах.

\section{Литература:}

1. Александрова И.Е. Математическое моделирование, системный анализ и синтез сложных технических объектов монография / И.Е. Александрова, Т.Е. Александрова / - Красноярск: Научно-инновационный центр, $2016 . \quad$ - 207 с. URL: https://elibrary.ru/item.asp?id=28851325

2. Аксенов К.А., Гончарова Н.В. Гибридное моделирование мультиагентных процессов преобразования ресурсов: монография. - М.: Издательский дом Академии Естествознания, 2019. - 222 с. ISBN 978-5-91327-606-3. URL: https://elibrary.ru/item.asp?id=41560696

3. Гурьянов В.И. Имитационное моделирование на UML SP: монография / В.И. Гурьянов. - Чебоксары: СПбГЭУ, 2014. - 135 c. URL: https://elibrary.ru/item.asp?id=23445783

4. Емельянов А.А., Булыгина О.В., Халин В.Г. Экономико-имитационное моделирование с элементами искусственного интеллекта: монография / А.А. Емельянов, О.В. Булыгина, В.Г. Халин. - М.: Неолит, 2018. - 160 с. ISBN 978-5-6040651-2-9. URL: https://www.elibrary.ru/item.asp?id=35657015

5. Евсеев В.О. Механизм разрешения противоречий и политическая система общества // Социально-политические науки. - 1990. - № 9. С. 77.

6. Евсеев В.О. Новая модель общественного развития // ЦИТИСЭ - 2016. - № 3. C. 1. URL: https://elibrary.ru/item.asp?id=29461676

7. Евсеев В.О. Имитационная модель: влияние экономических факторов на уровень политического доверия // ЦИТИСЭ. - 2017. - № 2. - С. 1. URL: https://elibrary.ru/item.asp?id=29461676

8. Медведев Н.П. Эффективность политических решений: консенсусная и представительская модели // Вопросы политологии. - 2018. - Т. 8, № 5 (33). - С. 15-22. URL: https://www.elibrary.ru/item.asp?id=34999211

9. Никишев В. К. Методы построения и исследования моделей динамических объектов и систем на основе компьютерного моделирования / В. К. Никишев. - Чебоксары: Изд-во Чувашского университета, 2014. - 332 с.

10. Сухарев О.С. Эволюционная экономическая теория институтов и технологий. Проблемы моделирования - M.: Ленанд, 2017. - 139 с. URL: https://www.elibrary.ru/item.asp?id=29405488

\section{References:}


1. Alexandrova I. E. Mathematical modeling, system analysis and synthesis of complex technical objects. Monograph. Krasnoyarsk, Research and innovation center Publ., 2016, 207 p. (In Russian) URL: https://elibrary.ru/item.asp?id=28851325

2. Aksenov K. A., Goncharova N. V. Hybrid modeling of multi-agent processes of resource transformation. Monograph. Moscow. Academy of natural Sciences Publ., 2019, 222 p. (In Russian) ISBN 978-5-91327-606-3. URL: https://elibrary.ru/item.asp?id=41560696

3. Guryanov V. I. Imitating modeling on UML SP. Monograph. Cheboksary. St. Petersburg state economic University in Cheboksary Publ., 2014, 135 p. (In Russian) URL: https://elibrary.ru/item.asp?id=23445783

4. Emelyanov A. A., Bulygina O. V., Khalin V. G. Economic simulation modeling with elements of artificial intelligence. Monograph. Moscow, Neolithic Publ., 2018, 160 p. ISBN 978-56040651-2-9. (In Russian) URL: https://www.elibrary.ru/item.asp?id=35657015

5. Evseev V. O. Mechanism for resolving contradictions and the political system of society. Socio-political Sciences, 1990, no. 9, pp. 77. (In Russian)

6. Evseev V. A. The new model of social development. CITISE, 2016, no. 3. (In Russian) URL: https://elibrary.ru/item.asp?id=29461676

7. Evseev V. O. Simulation model: the influence of economic factors on the level of political confidence. CITISE, 2017, no. 2. (In Russian) URL: https://elibrary.ru/item.asp?id=29461676

8. Medvedev N.P. The effectiveness of political decisions: consensus and representative models. Questions of political science, 2018, vol. 8, no. 5 (33), pp. 15-22. (In Russian) URL: https://www.elibrary.ru/item.asp?id=34999211

9. Nikishev V. K. Methods of construction and research of models of dynamic objects and systems based on computer modeling. Cheboksary, Chuvash UN-TA Publ., 2014, 332 p. (In Russian)

10. Sukharev O. S. Evolutionary economic theory of institutions and technologies. Modeling problems. Moscow, Lenand Publ., 2017, 139 p. (In Russian) URL: https://www.elibrary.ru/item.asp?id=29405488 